\title{
Microbiota of Human Gut-A Natural Remedy for Human Illness
}

\author{
Namrata Stasangi ${ }^{1}$, Devki $^{2}$, Varsha Gupta ${ }^{3}$, Deepesh Kumar Neelam ${ }^{4}$ \\ and Ravi Kant Rahi ${ }^{5}$ \\ Department of Microbiology, JECRC University, Jaipur, 303905, India.
}

Received: 18 Oct 2020 / Accepted: 16 Nov 2020/ Published online: 01 Jan 2021 *Corresponding Author Email: namrtasatsangi@gmail.com

\begin{abstract}
The human gut microbiomes play a very important role to maintain human health containing many bacteria, fungi, viruses, protozoan's etc. In gut microbiota most of microorganisms are commensally bacteria that play symbiotic relationship with host. The composition of gut microbes could be affected by many factors like diet, antibiotics, geography, culture, and environment. Gut dysbiosis causes many diseases from neurogenerative to cardiovascular diseases, obesity, and some cancers also. However, regular intake of probiotics helps to maintain the gut composition and prevent many diseases. Those people which do regular physical exercise they had, a very healthy gut composition as compared to those, who does not do any physical activity. Recently, a new bacterial strain has been discovered from Senegalese boy and a new strain from Enterocacea family. Excessive use of antibiotics modulates the gut microbiota and responsible for many diseases, it is found out that giving antibiotics in the early life of infants could alter their gut microbiota development. Unhealthy sleep-wake cycle also affect the gut microbiota. This review focus on current factors which are affecting the composition of gut microbes.
\end{abstract}

Keywords

Probiotics, antibiotics, gut microbes, diet.

\section{INTRODUCTION:}

Around 38 trillion bacterial cells are present in the human microbiota [1]. Around 1 billion microorganisms enters in the human stomach every day from outside environment, Up to 1800 genera \& 15000 species of microbes present in the GI tract [2]. The council of trillions of microbes that lives inside the gut is essential for human health [3]. Any sort of gut microbiota alternation leads to several chronic diseases like, inflammatory bowel diseases (IBS), obesity, cardiovascular diseases [4]. Factors such as diet, geography, socioeconomic status and culture are responsible for the composition of gut microbiota [5]. After some study it is discovered that the gut microbiota of children is largely affected by diet but not lifestyle, environment, ethnicity [6].
During the first years of life, the brain and microbiome develops rapidly allowing, excessive signals between gut and central nervous system (gutbrain axis) [7].

Chitoligosaccride (COS) increases the abundance of Fecalibacterium and Bacteriodes genera reducing pathogenic bacteria Klebisella genus [8]. The gut microbiota and their metabolites lead to cause colectoral adenoma which is precancerous lesions of colectoral cancer [9]. Melanoides are those components, which are present in wine, beer, biscuit, chocolate and breakfast cereals, it could increases production of short chain fatty acids and beneficial gut microbes [10]. A new bacterial strain SIT17 ${ }^{\top}$ was discovered in senaglese boy who had 
genome about 2.87 Mb long with $27.39 \mathrm{~mol} \% \mathrm{G}+\mathrm{C}$ content [11].

A new strain derived from Burkinabe woman named Marseille-Q0835 ${ }^{\top}$ is a new species in the family of enterocacea [12]. Several factors like dietary habits, metabolites, hormones which maintain the gut microbiota any disbalance leads to disease like rheumatoid arthritis \& diabetes mellitus [13]. Moderate Nonalcoholic beer along with active polyphenol and phenolic acid has positive affect on human health [14]. Human gut bacteria were co evolved with human host which, suggested that they have same micronutrient needs like humans [15]. Continuous intake of probiotics leads to ecological and genetic stability of gut microbiota, buckwheat honey regulates gut microbes [16]. Gut dysbiosis leads to neurodegenerative disorders [17]. The gut microbiome composition is affected by air pollutants, excessive exposure of air pollutants leads to decrease in gut microbial diversity [18].

\section{GUT MICROBE'S STRUCTURE\& COMPOSITION:}

Probiotic bacteria helps to generate lactate in gut which leads to increase in butyrate levels and these butyrate levels promote growth of meant commensally bacteria, time of wound healing and inflammatory response of the human body [19]. Sini decoction (SDC) could enhance the symptom and pathology linked with sepsis in (CLP) cercal ligation and puncture, by modulating the gut microbiota [20]. Several studies indicated lower consumption of vitamin E could; alter the gut microbiota composition [21]. Bifidobacterial supplements modulate the gut microbiota in such way that, it reduces the allergic inflammation [22]. Excessive weight gain is related to gut microbiota and those people who have high bacteriodes in their gut are responsible for excessive weight gain [23].

Mutation in single host gene could affect the composition of gut microbes [24]. The HIV virus alters the gut microbiota however, use of antiretroviral therapy for long time leads to richness of gut microbiota [25]. The presence of bacterial composition of Bifidobacteriales and Lactobacillus in the gut shows sensitivity towards inhales allergens [26]. Modulation of gut microbiota composition leads to cardiovascular dieases \& coronary artery diseases [27]. The gut microbiota composition of SARS-COVID infected people is modulated and increased in the abundance of opportunistic pathogen [28]. Changes could be seen in composition of gut bacterial community in those Patients which were infected with multiple sclerosis [29].
Attention-deficit/ hyperactivity disorder (ADHD) has altered gut composition with variation in specific genus Ruminococcus [30]. Age is the important factor for altered gut microbiota of major depressive disorder (MDD) [31]. Diverse vegetation around homes affects the gut microbial composition \& health related changes [32]. The chemical substances of prebiotics and gut microbes both are responsible for gas production in human body and they are also responsible for the manufacturing of short chain fatty acid (SCFs) and byproduct of (SCFs) has physiological effects in human body [33]. Consumption of kombucha, (a mixture of live yeast and bacteria) can restore gut microbiota composition [34]. Lifestyle modification and drug intake alter the gut microbiota [35]. Gut microbes composition also affect the quality sleep, those persons which have good ratio Firmicutes and Bacteriodes in their gut microbiota pursue better quality sleep [36].

\section{GUT MICROBE'S ROLE IN HUMAN BODY:}

The human gut microbes are easily affected by the toxic environment agents that we intake from food [37]. Intermediate fasting, unhealthy eating habits, ph and water quality also disfigured the composition of gut micro biota [38]. In breast feeding the main component that is taken by the infant from the outside environment (HMO) human milk oligosaccaride which is, responsible for increase in the abundance of bifidobacteria in gut community [39]. Athlete's microbiota undergoes many changes increase in much bacterial community which is helpful for their incredible physical performance [40]. That person who lives at higher altitude has different gut microbial composition which is due to different genetic factors and environmental factors [41]. Cultural variations in feeding practices, hygiene, and delivery mode are important factors to alter the gut microbiota [42].

The human soon starts developing gut micro biota since birth and acquire gut microbes variability according to their environment and intrinsic factors [43]. The occurrence of Fusobacteria, Shigella, and Streptococcus are responsible for pathogenicity of Kawasaki disease (pediatric diseases) [44]. Recently banned product triclosan which is used in consumer soaps has been found in urine, milk, human milk thus modulating the gut microbial community [45]. Environmental chemicals such as (bisphenols, phthalates, heavy metals, pesticides, persistent organic molecules could modulate the gut microbiota [46]. In response to environmental chemicals the altered gut microbiotas are Causable 
for many diseases pathogen which leads to many diseases like autoimmune diseases [47].

Environmental exposures such as metals have diverse effects on prenatal gut microbiome development and it leads to many harmful health effects [48]. Blueberry consumption improves gut microbiota and provides other health benefits [49]. Polyphenols supplement intake increase the abundance of Bifidobacterium, Lactobacillus and reduce pathogenic bacteria Clostridium and contribute to maintain human health [50]. Unhealthy sleep-wake shifts which cause acute circadian rhythm affect the human gut microbes [51]. Estrobolome are those gut bacteria's that has the capability to control estrogen, who plays a key role in most of the breast cancer thus it is discovered that the gut microbiota contribute in overall health of humans including breast health [52]. The bacterial family Christensenellaceae and archeal Methanobacteriacea are present more in lean people as compared to obese and linked to lower BMI of these people [53]. Use of microalgae as prebiotics rich in (fiber, fatty acids and protein) which is effective in weight loss [54].

\section{ROLE OF ANTIBIOTICS ON GUT MICROBES:}

Antibiotics used to treat infections and fight with pathogenic organism but also affect commensally bacteria, causing dysbiosis and leads to infection [55]. Antibiotics affecting the intestinal microbiota by increasing opportunistic pathogen which leads to many microbial disorders, adding vancomycin antibiotic increased the chances of infection [56]. Studies indicated that combination of polymixin and amoxicillin antibiotics lessen the drug resistance in the gut micro biota [57]. Antibiotic resistant genes (ARB) and antibiotic resistance has outstanding impact on gut health [58]. Apart from health benefits to human body the Antibiotics, has adverse effects on gut which leads to Antibiotic-associated diarrhea [AAD] However, probiotics helps to prevent this [AAD] [59].

Using antibiotics regularly from early life leads to inflammatory bowel diseases [60]. Some antibiotics cindmycin and ciprofloxin which are used in Clostridiodes difficile-associated diseases (CDAD) are used to increase the risk of (CDAD) [61]. (Clostrdiodes difficle infection) is mainly cause due to fomer use of antibiotics which modulate the metabolic function and composition of gut microbes leads to decease' in colonization of microbes and cause (CDC) [62]. Long term usage of antibioic leads to loss of intestinal microbial diversity and microbial metabolic functions which increases the chances of atherosclerosis [63].
Probiotics along with antibiotics Probiotics along with antibiotics does not alter the gut microbial diversity [64].

The effect of intrapartum antibiotics on infants is that it modulates the gut microbiome, of infants [65]. As far as it is known that gut microbes were altered by non-antibiotics drugs but now it is found out that gut microbes can also affect the drugs by enzymatically disfiguring the structure of drug and change its bioavailability [66]. The commensal bacteria obtain the antibiotic resistance genes can moderate protection of pathogens from bactericidal effects of antibiotics [67]. The antibiotic named ceftraixone modulate the gut microbiota and Lactobacillus reduces the side effects of antibiotics by maintaining steadiness of intestinal micro biota [68]. Antibiotics help to facilite the autoimmunity by causing gut dysbiosis. And they have the potential to increase the disease activity [69]. By adding antibiotics in early life of infants may alter the gut microbiota [70]. To particularly treats kwashiorkar diseases usage of antibiotic therapy along with probiotics and antioxidants to suppress the overgrowth of bacterial communities which are resistant of penicillin [71].

Recent studies revealed that, by taking dietary proteins in our diet helps to regulate biosynthesis and catabolism of serotonin by, modulating distinctive microbes [72]. Diet plays a very important role to maintain the composition and functioning of the gut microbes [73]. Dietry cellulose like apple skin, legumes, peas, nuts maintains the gut homeostasis by modulating gut microbiota. Whatever food we are taking it has greater impact on our body, unhealthy dietary habits leads to many diseases like inflammatory bowel syndrome [IBS] and functional gut disorders [74]. Those people which has started including probiotics in their diet it is found out that they had developed betterment in depression and anxiety and probiotics helps them by suppressing biological markers of stress [75].

Recent studies revealed that by adding high fat and low carb diet alter gut microbiota [76]. Diet has very small effects on gut community but greater impact on surrounding environment [77]. Diet has an enrollment for specific carbs to reshape the met genomic composition of gut microbial community with the help of specific bacterial taxa [78]. By adding dietary fibers, short chain fatty acids, are helpful in growth of beneficial gut microbes, which can protect the human body from cancer and promote other health benefits [79]. It is revealed that having a good dietary components helps to prevents Alzheimer diseases [80]. By adding specific food in human diet 
leads to change the greater composition of some specific bacteria [81].

A modified mediterrian diet leads to alter the gut microbiota composition and functionality as Compared western diet [82]. Dietary intake of whole grain, red and processed meat increases the risk of colectoral cancer [83]. Some evidences suggested that red wine and tea-derived polyphenols reduce the composition of beneficial bacteria [84]. By balancing gut microbial composition Xylooligosaccride (xos) can reduce colonic inflammation [85]. Nutrients like fiber, lipid and protein are very useful in prenatal development [86].
Both quality and quantity of dietary foods can affect the gut bacteria [87].

Adding symbiotics supplement in the diet modulate the gut micro biota and increases the beneficial bacteria [88]. A well-equipped nutrient vegan diet affects the bacterial composition and metabolic pathways of gut microbiota [89]. Consumption of whole grain is helpful to prevent some metabolic diseases [90]. Modern supplement food; processed foods can modulate the gut micro biota in leads to many diseases [91]. Bioactive cocoa gut metabolites can alter the gut micro biota and promote the growth of beneficial bacteria and inhibit the growth of pathogenic ones [92].

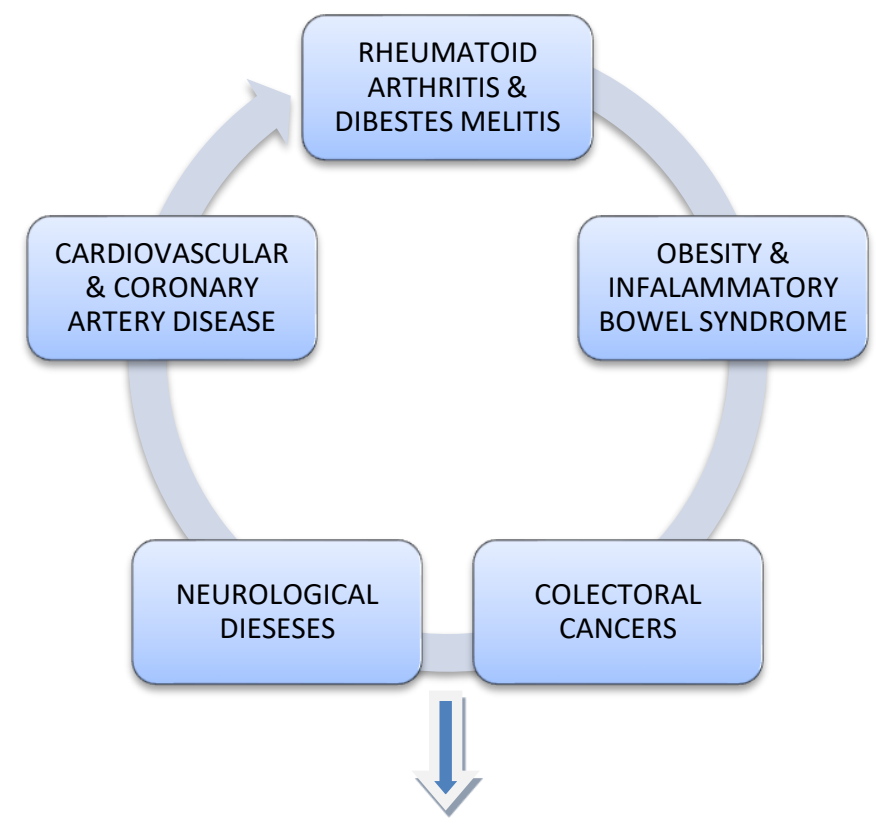

GUT MICROBES

Figure 1 Diseases caused by dysbiosis of microbes 


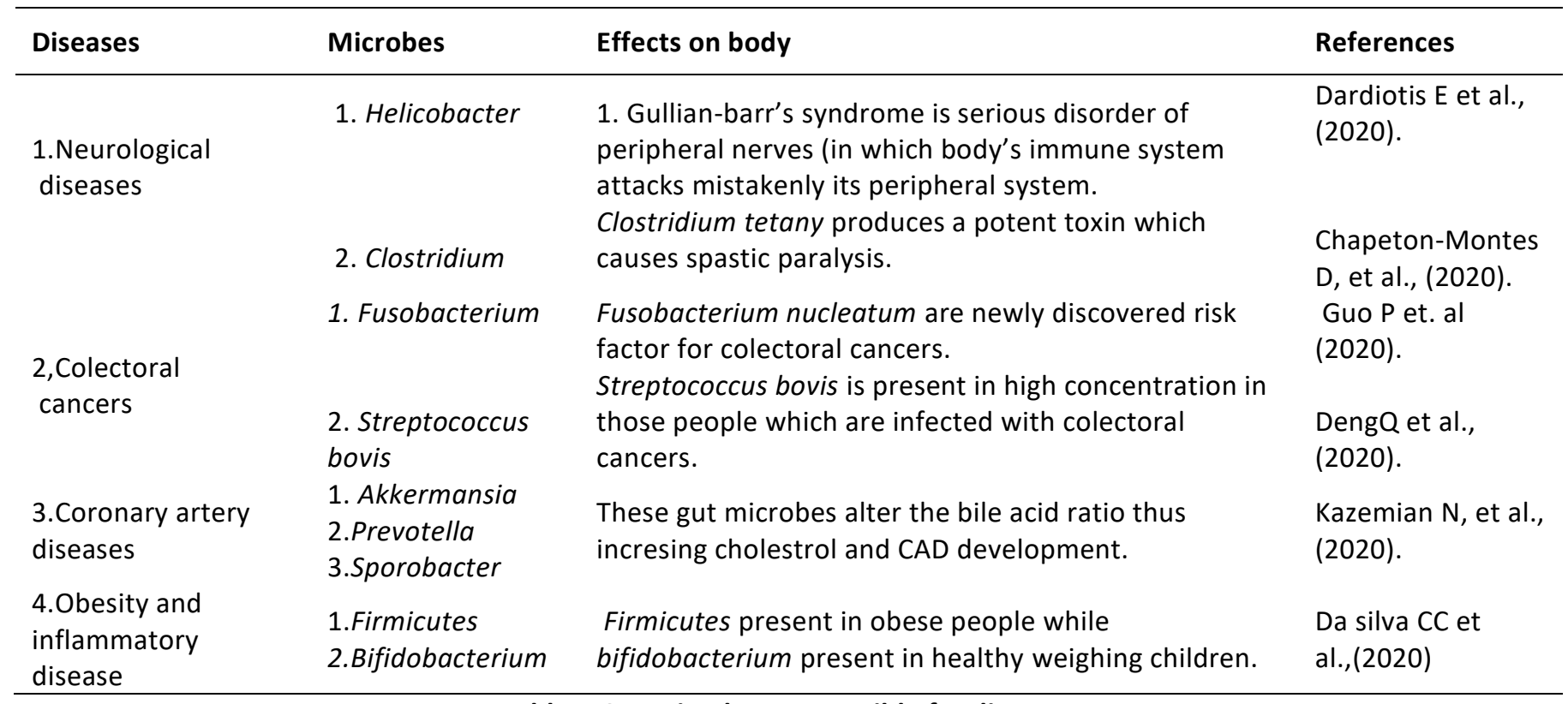

Table 1 Gut microbes responsible for diseases

\section{CONCLUSION:}

Earlier research on the gut microbes provided several evidences that gut microbes play a crucial role to maintain healthy body. On the other hand it is proved that and diet, antibiotics have greater impact on gut microbial composition, which is linked to mainly health issues like cardiovascular diseases, obesity, neurological diseases and rheumatoid arthritis. On the other hand previous research also showed that a healthy gut microbe's composition also helps in weight loss. Healthy eating habits with added probiotics proved to be very useful for the gut microbes. However, there are some other factors in which further research are needed; we need to work upon those antibiotics or drugs which are affecting the gut microbial composition. Further work is needed to research on those harmful chemical or compounds in our daily diet or environment which is effecting our gut microbial composition and affecting human health.

\section{ACKNOWLEDGEMENTS:}

All listed author(s) are thankful to JECRC University for providing the related support to compile this work.

\section{REFRENCES:}

1. Liu $Y$, Lou $X$. Type 2 diabetes mellitus-related environmental factors and the gut microbiota: emerging evidence and challenges.Clinics.2020; 75. : 1807-5932.

2. Christian.U, Ridel, Andreas Schweiretz and Markus Egert. The stomach and small and large intestinal microbiomes UK by CPI group, (2014).
3. Deering KE, Devine A,O'Sullivan TA, Lo J, Boyce MC, Christophersen CT. Characterizing the composition of the pediatric gut microbiome: a systematic review.Nutrients.2020 Jan; 12(1):16.

4. Altamura F, Maurice CF, Castagner B. Drugging the gut microbiota: toward rational modulation of bacterial composition in the gut.Current opinion in chemical biology.2020 Jun 1; 56:10-5.

5. Kaur K, Khatri I, Akhtar A, Subramanian S, Ramya TN. Metagenomics analysis reveals features unique to Indian distal gut microbiota. PloS one.2020 Apr 8; 15(4):e0231197.

6. Khine WW, Zhang $Y$, Goie GJ, Wong MS, Liong M, Lee YY, Cao H, Lee YK.Gut microbiome of pre-adolescent children of two ethnicities residing in three distant cities. Scientific reports.2019 May 24; 9(1):1-0.

7. Bonham KS, Bruchhage MM, Rowland $S$, Volpe AR, Dyer K, D'Sa V, Huttenhower C, Deoni SC, Klepac-Ceraj V, RESONANCE Consortium. Gut microbes and their genes are associated with brain development and cognitive function in healthy children.BioRxiv. 2020 Jan 1.02.13.944181.

8. Liu W, Li X, Zhao Z, Pi X, Meng Y, Fei D, Liu D, Wang X. Effect of chitooligosaccharides on human gut microbiota and antiglycation. Carbohydrate Polymers.2020 May 11:116413.

9. Kim $M$, Vogtmann E, Ahlquist DA, Devens ME, Kisiel JB, Taylor WR, White BA, Hale VL, Sung J, Chia N, Sinha R. Fecal Metabolomic Signatures in Colorectal Adenoma Patients Are Associated with Gut Microbiota and Early Events of Colorectal Cancer Pathogenesis.Mbio.2020 Feb 25; 11(1).

10. Traore SI, Ngom II, Lo Cl, Di Pinto F, Sokhna C, Fournier $P E$, Raoult D, Fenollar F. Detailed description of Senegalia massiliensis strain Marseille-P2130T, a bacterium isolated from the human gut. New Microbes and New Infections.2020 May 23:100700. 
11. Gouba N, Yimagou EK, Hassani Y, Drancourt M, Fellag $\mathrm{M}$, Fonkou MD. Enterococcus burkinafasonensis sp. Nov. isolated from human gut microbiota.New Microbes and New Infections. 2020 Jun 1:100702.

12. Vandana UK, Barlaskar NH, Gulzar AB, Laskar IH, Kumar D, Paul P, Pandey P, Mazumder PB.Linking gut microbiota with the human diseases. Bioinformation .2020; 16(2):196.

13. Hernández-Quiroz F, Nirmalkar K, Villalobos-Flores LE, Murugesan S, Cruz-Narváez Y, Rico-Arzate E, HoyoVadillo C, Chavez-Carbajal A, Pizano-Zárate ML, García-Mena J. Influence of moderate beer consumption on human gut microbiota and its impact on fasting glucose and $\beta$-cell function.Alcohol.2020 Jun $1 ;$ 85:77-94.

14. Celis Al, Relman DA. Competitors versus Collaborators: Micronutrient Processing by Pathogenic and Commensal Human-Associated Gut Bacteria. Molecular Cell.2020 May 21; 78(4):570-6.

15. Ma C, Wasti S, Huang S, Zhang Z, Mishra R, Jiang S, You $\mathrm{Z}$, Wu Y, Chang H, Wang Y, Huo D. The gut microbiome stability is altered by probiotic ingestion and improved by the continuous supplementation of galactooligosaccharide. Gut microbes. 2020 Nov 9; 12(1):1785252.

16. Jiang L, Xie M, Chen G, Qiao J, Zhang H, Zeng X. Phenolics and Carbohydrates in Buckwheat Honey Regulate the Human Intestinal Microbiota. EvidenceBased Complementary and Alternative Medicine .2020 Feb 26; 2020.

17. Khan MS, Ikram M, Park JS, Park TJ, Kim MO. Gut Microbiota, Its Role in Induction of Alzheimer's Disease Pathology, and Possible Therapeutic Interventions: Special Focus on Anthocyanins. Cells. 2020 Apr; 9(4):853.

18. Fouladi F, Bailey MJ, Patterson WB, Sioda M, Blakley IC, Fodor AA, Jones RB, Chen Z, Kim JS, Lurmann F, Martino $C$. Air pollution exposure is associated with the gut microbiome as revealed by shotgun metagenomic sequencing. Environment International. 2020 May 1; 138:105604.

19. Ghyselinck J, Verstrepen L, Moens F, Van den Abbeele P, Said J, Smith B, Bjarnason I, Basit AW, Gaisford S. A 4-strain probiotic supplement influences gut microbiota composition and gut wall function in patients with ulcerative colitis.International Journal of Pharmaceutics. 2020 Sep 25; 587:119648.

20. Wang $W$, Chen $Q$, Yang $X$, Wu J, and Huang F. Sini decoction ameliorates interrelated lung injury in septic mice by modulating the composition of gut microbiota.Microbial Pathogenesis. 2020 Mar 1; 140:103956.

21. Choi $Y$, Lee $S, \operatorname{Kim} S$, Lee J, Ha J, Oh H, Lee $Y, \operatorname{Kim} Y$, Yoon Y. Vitamin E ( $\alpha$-tocopherol) consumption influences gut microbiota composition. International Journal of Food Sciences and Nutrition.2020 Feb 17; 71(2):221-5.

22. Kirjavainen PV, Arvola T, Salminen SJ, Isolauri E. Aberrant composition of gut microbiota of allergic infants: a target of bifidobacterial therapy at weaning.Gut.2002 Jul 1; 51(1):51-5.
23. Collado MC, Isolauri E, Laitinen K, Salminen S. Distinct composition of gut microbiota during pregnancy in overweight and normal-weight women. The American journal of clinical nutrition.2008 Oct 1; 88(4):894-9.

24. Khachatryan ZA, Ktsoyan ZA, Manukyan GP, Kelly D, Ghazaryan KA, Aminov RI.Predominant role of host genetics in controlling the composition of gut microbiota.PloS one. 2008 Aug 26; 3(8):e3064.

25. Flygel TT, Sovershaeva E, Claassen-Weitz S, Hjerde E, Mwaikono KS, Odland J $\varnothing$, Ferrand RA, Mchugh G, Gutteberg TJ, Nicol MP, Cavanagh JP.Composition of Gut Microbiota of Children and Adolescents with Perinatal Human Immunodeficiency Virus Infection Taking Antiretroviral Therapy in Zimbabwe.The Journal of Infectious Diseases. 2020 Jan 14; 221(3):483-92.

26. Nomura A, Matsubara A, Goto S, Takahata J, Sawada K, Ihara K, Nakaji S. Relationship between gut microbiota composition and sensitization to inhaled allergens. Allergology International69, 2020 Jan 22. , 3,437-442.

27. Zuo T, Liu Q, Zhang F, Lui GC, Tso EY, Yeoh YK, Chen Z, Boon SS, Chan FK, Chan PK, Ng SC. Depicting SARSCoV-2 faecal viral activity in association with gut microbiota composition in patients with COVID19.Gut.2020 Jul 19,-2020-322294.

28. Castillo-Alvarez F, Perez-Matute P, Oteo JA, MarzoSola ME.The influence of interferon $\beta-1 b$ on gut microbiota composition in patients with multiple sclerosis.Neurología (English Edition). 2020 May 31. 2173-5808.

29. Szopinska-Tokov J, Dam S, Naaijen J, Konstanti P, Rommelse N, Belzer C, Buitelaar J, Franke B, Aarts E, Arias Vasquez $A$. Investigating the gut microbiota composition of individuals with attention-deficit/ hyperactivity disorder and association with symptoms.Microorganisms. 2020 Mar; 8(3):406.

30. Chen JJ, He S, Fang L, Wang B, Bai SJ, Xie J, Zhou CJ, Wang W, Xie P. Age-specific differential changes on gut microbiota composition in patients with major depressive disorder. Aging (Albany NY).2020 Feb 15; 12(3):2764.

31. Parajuli A, Hui N, Puhakka R, Oikarinen $S$, Grönroos $M$, Selonen VA, Siter N, Kramna L, Roslund MI, Vari HK, Nurminen N. Yard vegetation is associated with gut microbiota composition. Science of the Total Environment.2020 Apr 15; 713:136707.

32. Yu X, Gurry T, Richardson HS, Alm E. Prebiotics and community composition influence gas production of the human gut microbiota.BioRxiv.2020 Jan 1.01.30.928085.

33. Hicke, John, and Emily Nelson.,Kombucha's Effect on the Composition of the Human Gut Microbiota, its Connection to Disease, and its Application to Treating an Enteric Strain of Salmonella,112.(2020).

34. Dannenberg L, Zikeli D, Benkhoff $\mathrm{M}$, Ahlbrecht $\mathrm{S}$, Kelm M, Levkau B, Polzin A. Targeting the human microbiome and its metabolite TMAO in cardiovascular prevention and therapy. Pharmacology \& Therapeutics.2020 May 22:107584. 
35. Grosicki GJ, Riemann BL, Flatt AA, Valentino $T$, Lustgarten MS. Self-Reported Sleep Quality Is Associated With Gut Microbiome Composition in Young, Healthy Individuals: A Pilot Study. Sleep Medicine.2020 Apr 23, 73, 76-81.

36. Tu P, Chi L, Bodnar W, Zhang Z, Gao B, Bian X, Stewart J, Fry R, Lu K. Gut Microbiome Toxicity: Connecting the Environment and Gut Microbiome-Associated Diseases. Toxics.2020 Mar; 8(1):19.

37. Bajinka O, Tan Y, Abdelhalim KA, Özdemir G, Qiu X. Extrinsic factors influencing gut microbes, the immediate consequences and restoring eubiosis. AMB Express.2020 Dec; 10(1):1-1.

38. Vandenplas $Y$, Carnielli VP, Ksiazyk J, Luna MS, Migacheva N, Mosselmans JM, Picaud JC, Possner M, Singhal A, Wabitsch $M$. Factors affecting early-life intestinal microbiota development. Nutrition.2020 Oct 1; 78:110812.

39. Kulecka M, Fraczek B, Mikula M, Zeber-Lubecka N, Karczmarski J, Paziewska A, Ambrozkiewicz F, Jagusztyn-Krynicka K, Cieszczyk P, Ostrowski J. The composition and richness of the gut microbiota differentiate the top Polish endurance athletes from sedentary controls. Gut Microbes. 2020 May 14:1-1.

40. Li K, Peng W, Zhou Y, Ren Y, Zhao J, Fu X, Nie Y. Host Genetic and Environmental Factors Shape the Composition and Function of Gut Microbiota in Populations Living at High Altitude.BioMed Research International.2020 Feb 28; 2020.

41. Quin C, Gibson DL. Human behavior, not race or geography, is the strongest predictor of microbial succession in the gut bacteriome of infants. Gut Microbes.2020 Apr 7:1-29.

42. Xu J, Lawley B, Wong G, Otal A, Chen L, Ying TJ, Lin X, Pang WW, Yap F, Chong YS, Gluckman PD. Ethnic diversity in infant gut microbiota is apparent before the introduction of complementary diets. Gut Microbes. 2020 May 18:1-2.

43. Khan I, Li XA, Law B, U KI, Pan BQ, Lei C, Hsiao WW.Correlation of gut microbial compositions to the development of Kawasaki disease vasculitis in children.Future Microbiology.2020 Apr (0).

44. Mahalak KK, Firrman J, Lee JJ, Bittinger K, Nuñez A, Mattei LM, Zhang H, Fett B, Bobokalonov J, ArangoArgoty G, and Zhang L. Triclosan has a robust, yet reversible impact on human gut microbial composition in vitro. Plos one.2020 Jun 25; 15(6):e0234046.

45. Chiu K, Warner G, Nowak RA, Flaws JA, Mei W.The impact of environmental chemicals on the gut microbiome.Toxicological Sciences. 2020 Aug 1; 176(2):253-84.

46. Khan MF, Wang H. Environmental Exposures and Autoimmune Diseases: Contribution of Gut Microbiome. Frontiers in immunology.2020 Jan 10; 10:3094.

47. Laue HE, Moroishi Y, Jackson BP, Palys TJ, Madan JC, Karagas MR. Nutrient-toxic element mixtures and the early postnatal gut microbiome and in a United States longitudinal birth cohort. Environment International .2020 May $1 ; 138: 105613$.
48. Ntemiri A, Ghosh TS, Gheller ME, Tran TT, Blum JE, Pellanda P, Vlckova K, Neto MC, Howell A, ThalackerMercer A, O'Toole PW. Whole Blueberry and Isolated Polyphenol-Rich Fractions Modulate Specific Gut Microbes in an In Vitro Colon Model and in a Pilot Study in Human Consumers. Nutrients.2020 Sep; 12(9):2800.

49. Ma G, Chen Y. Polyphenol supplementation benefits human health via gut microbiota: A systematic review via meta-analysis. Journal of Functional Foods.2020 Mar 1; 66:103829.

50. Liu Z, Wei ZY, Chen J, Chen K, Mao X, Liu Q, Sun Y, Zhang Z, Zhang Y, Dan Z, Tang J. Acute Sleep-Wake Cycle Shift Results in Community Alteration of Human Gut Microbiome.Msphere.2020, Feb 26; 5(1).

51. Bodai, B. I., \& Nakata, T. E. (2020). Breast Cancer: Lifestyle, the Human Gut Microbiota/Microbiome, and Survivorship.The Permanente journal, 24, 19.129.

52. Ruaud A, Esquivel-Elizondo $S$, de la Cuesta-Zuluaga J, Waters JL, Angenent LT, Youngblut ND, Ley RE. Syntrophy via Interspecies H2 Transfer between Christensenella and Methanobrevibacter Underlies Their Global Cooccurrence in the Human Gut.Mbio.2020 Feb 25; 11(1).

53. Jin JB, Cha JW, Shin IS, Jeon JY, Cha KH, and Pan $\mathrm{CH}$.Supplementation with Chlorella vulgaris, Chlorella protothecoides, and Schizochytrium sp. increases propionate-producing bacteria in in vitro human gut fermentation.Journal of the Science of Food and Agriculture. 2020 May; 100(7):2938-45.

54. Patton L, Li N, Garrett TJ, Ruoss JL, Russell JT, de la Cruz D, Bazacliu C, Polin RA, Triplett EW, Neu J. Antibiotics effects on the fecal metabolome in preterm infants. Metabolites. 2020 Aug; 10(8):331.

55. Liu L, Wang Q, Wu X, Qi H, Das R, Lin H, Shi J, Wang S, Yang J, Xue Y, Mao D. Vancomycin exposure caused opportunistic pathogens bloom in intestinal microbiome by simulator of the human intestinal microbial ecosystem (SHIME).Environmental Pollution. 2020 Mar 18:114399.

56. Liu, Lei, Ranjit Das, Pengcheng Suo, Huai Lin, Hongmei Qi, Siyi Wang, and Xiaojun Zuo Human gut microbiota evaluation and comparation after the separate or combined antibiotics exposure using the simulator of human intestinal microbial ecosystem (SHIME), 2020,4; $1-17$

57. Amarasiri M, Sano D, Suzuki S. Understanding human health risks caused by antibiotic resistant bacteria (ARB) and antibiotic resistance genes (ARG) in water environments: Current knowledge and questions to be answered.Critical Reviews in Environmental Science and Technology. 2020 Oct 1; 50(19):2016-59.

58. Mekonnen SA, Merenstein D, Fraser CM, Marco ML. Molecular mechanisms of probiotic prevention of antibiotic-associated diarrhea. Current Opinion in Biotechnology.2020 Feb 1; 61:226-34.

59. Nguyen LH, Örtqvist AK, Cao Y, Simon TG, Roelstraete $B$, Song $M$, Joshi AD, Staller K, Chan AT, Khalili H, Olén $O$. Antibiotic use and the development of inflammatory bowel disease: a national case-control 
study in Sweden.The Lancet Gastroenterology \& Hepatology. 2020 Nov 1; 5(11):986-95.

60. Kester JC, Brubaker DK, Velazquez J, Wright C, Lauffenburger DA, Griffith LG. Clostridioides difficileAssociated Antibiotics Alter Human Mucosal Barrier Functions by Microbiome-Independent Mechanisms .Antimicrobial agents and chemotherapy. $2020 \mathrm{Mar}$ 24; 64(4).

61. Schnizlein MK, Vendrov KC, Edwards SJ, Martens EC, Young VB. Dietary xanthan gum alters antibiotic efficacy against the murine gut microbiota and attenuates Clostridioides difficile colonization.Msphe re.2020 Feb 26; 5(1).

62. Kappel BA, De Angelis L, Heiser M, Ballanti $M$, Stoehr R, Goettsch C, Mavilio M, Artati A, Paoluzi OA, Adamski J, Mingrone G. Cross-omics analysis revealed gut microbiome-related metabolic pathways underlying atherosclerosis development after antibiotics treatment. Molecular Metabolism.2020 Mar 13:100976.

63. Das DJ, Shankar A, Johnson JB, Thomas S. Critical insights into antibiotic resistance transferability in probiotic Lactobacillus. Nutrition.2020 Jan 1; 69:110567.

64. Coker MO, Hoen AG, Dade E, Lundgren S, Li Z, Wong $A D$, Zens MS, Palys TJ, Morrison HG, Sogin ML, Baker ER. Specific class of intrapartum antibiotics relates to maturation of the infant gut microbiota: a prospective cohort study. BJOG: An International Journal of Obstetrics \& Gynaecology. 2020 Jan; 127(2):217-27.

65. Weersma RK, Zhernakova A, Fu J. Interaction between drugs and the gut microbiome.Gut. 2020 May 14. 69:1510-1519.

66. Gjonbalaj M, Keith JW, Do MH, Hohl TM, Pamer EG, Becattini S. Antibiotic degradation by commensal microbes shields pathogens. Infection and Immunity .2020 Mar 23; 88(4).

67. Miao $Z$, Cheng $R$, Zhang $Y$, Liang $H$, Jiang $F$, Shen $X$, Chen $G$, Zhang $Q$, He F, Li M. Antibiotics can cause weight loss by impairing gut microbiota in mice and the potent benefits of lactobacilli. Bioscience, Biotechnology, and Biochemistry.2020 Feb 1; 84(2) :411-20.

68. Vangoitsenhoven R, Cresci GA. Role of Microbiome and Antibiotics in Autoimmune Diseases. Nutrition in Clinical Practice.2020 Jun; 35(3):406-16.

69. Chen LW, Xu J, Soh SE, Aris IM, Tint MT, Gluckman PD, Tan KH, Shek LP, Chong YS, Yap F, Godfrey KM. Implication of gut microbiota in the association between infant antibiotic exposure and childhood obesity and adiposity accumulation.International Journal of Obesity. 2020, Apr 22:1-3.

70. Alou MT, Bachar D, Levasseur A, Brah S, Alhousseini D, Sokhna C, Diallo A, Wieringa F, Million M, Raoult D. Gut microbiota alteration is characterized by a proteobacteria and fusobacteria bloom in kwashiorkor and a bacteroidetes paucity in marasmus.Scientific reports. 2019 Jun 24; 9(1):1-3.

71. Xie Y, Wang C, Zhao D, Wang C, Li C. Dietary Proteins Regulate Serotonin Biosynthesis and Catabolism by
Specific Gut Microbes. Journal of Agricultural and Food Chemistry.2020 May 4.

72. Holscher HD. Gut Microbes: Nuts about Fatty Acids. The Journal of Nutrition.2020 Apr 1; 150(4):652-3.

73. Kim Y, Hwang SW, Kim S, Lee YS, Kim TY, Lee SH, Kim SJ, Yoo HJ, Kim EN, Kweon MN. Dietary cellulose prevents gut inflammation by modulating lipid metabolism and gut microbiota. Gut Microbes. 2020 Mar 6:1-8.

74. James SC, Fraser K, Young W, McNabb WC, Roy NC. Gut microbial metabolites and biochemical pathways involved in irritable bowel syndrome: Effects of diet and nutrition on the microbiome. The Journal of Nutrition.2020 May 1; 150(5):1012-21.

75. Taylor, AM, Holscher HD.A review of dietary and microbial connections to depression, anxiety, and stress. Nutritional neuroscience.2020 Mar 3; 23(3) :237-50.

76. Wan Y, Tang J, Li J, Li J, Yuan J, Wang F, Li D. Contribution of diet to gut microbiota and related host cardiometabolic health: diet-gut interaction in human health. Gut Microbes.2020 Jan 23:1-7.

77. Macke E, Callens M, Massol F, Vanoverberghe I, De Meester L, Decaestecker E. Diet and Genotype of an Aquatic Invertebrate Affect the Composition of FreeLiving Microbial Communities. Frontiers in microbiology.2020 Mar 17; 11:380.

78. Mack A, Bobardt JS, Haß A, Nichols KB, Schmid RM, Stein-Thoeringer CK. Changes in gut microbial metagenomic pathways associated with clinical outcomes after the elimination of malabsorbed sugars in an IBS cohort. Gut microbes. 2020 May 3; 11(3):620-31.

79. Tao J, Li S, Gan RY, Zhao CN, Meng X, Li HB. Targeting gut microbiota with dietary components on cancer: Effects and potential mechanisms of action. Critical Reviews in Food Science and Nutrition.2020 Mar 25; 60(6):1025-37.

80. Zhang M, Zhao D, Zhou G, Li C. Dietary Pattern, Gut Microbiota, and Alzheimer's Disease. Journal of Agricultural and Food Chemistry.2020 Feb 28. 68 (46), 12800-12809.

81. Cox IJ, Idilman R, Fagan A, Turan D, Ajayi L, Le Guennec $A D$, Taylor-Robinson SD, Karakaya F, Gavis E, Andrew Atkinson R, Williams R. Metabolomics and microbial composition increase insight into the impact of dietary differences in cirrhosis. Liver International. 2020 Feb; 40(2):416-27.

82. Song $M$, Chan AT, Sun J. Influence of the gut microbiome, diet, and environment on risk of colorectal cancer. Gastroenterology.2020 Jan 1; 158(2):322-40.

83. Yang $Q$, Liang $Q$, Balakrishnan B, Belobrajdic DP, Feng QJ, Zhang W. Role of dietary nutrients in the modulation of gut microbiota: A narrative review. Nutrients.2020 Feb; 12(2):381.

84. Fei $Y$, Wang $Y$, Pang $Y$, Wang $W$, Zhu $D$, Xie $M$, Lan $S$, Wang Z. Xylooligosaccharide Modulates Gut Microbiota and Alleviates Colonic Inflammation Caused by High Fat Diet Induced Obesity. Frontiers in physiology.2020 Jan 22; 10:1601. 
85. Hernández-Quiroz F, Nirmalkar K, Villalobos-Flores LE, Murugesan S, Cruz-Narváez Y, Rico-Arzate E, HoyoVadillo C, Chavez-Carbajal A, Pizano-Zárate ML, García-Mena J. Influence of moderate beer consumption on human gut microbiota and its impact on fasting glucose and $\beta$-cell function. Alcohol.2020 Jun 1; 85:77-94.

86. Scholz M, Staudacher H, Fava F, Tuohy K, Whelan K. Food \& Nutrition: The driving factors of our gut microbes.Proceedings of the Nutrition Society.2020; 79(OCE2).

87. Sergeev IN, Aljutaily T, Walton G, Huarte E. Effects of synbiotic supplement on human gut microbiota, body composition and weight loss in obesity. Nutrients. 2020 Jan; 12(1):222.

88. Sakkas H, Bozidis P, Touzios C, Kolios D, Athanasiou G, Athanasopoulou E, and Gerou I, Gartzonika C. Nutritional Status and the Influence of the Vegan Diet on the Gut Microbiota and Human Health. Medicina .2020 Feb; 56(2):88.

89. Tieri $M$, Ghelfi $F$, Vitale $M$, Vetrani $C$, Marventano S, Lafranconi A, Godos J, Titta L, Gambera A, Alonzo E, Sciacca $S$. Whole grain consumption and human health: an umbrella review of observational studies. International Journal of Food Sciences and Nutrition.2020 Jan 21:1-0.

90. $\mathrm{Wu} \mathrm{Q}$, Chen T, El-Nezami H, Savidge TC. Food ingredients in human health: Ecological and metabolic perspectives implicating gut microbiota function. Trends in Food Science \& Technology.2020 Apr 18.

91. Sorrenti V, Ali S, Mancin L, Davinelli S, Paoli A, Scapagnini G. Cocoa Polyphenols and Gut Microbiota Interplay: Bioavailability, Prebiotic Effect, and Impact on Human Health.Nutrients. 2020 Jul; 12(7):1908.
92. Chapeton-Montes D, Plourde L, Deneve C, Garnier D, Barbirato F, Colombié V, Demay S, Haustant G, Gorgette O, Schmitt C, and Thouvenot C. Tetanus Toxin Synthesis is Under the Control of a Complex Network of Regulatory Genes in Clostridium tetani. Toxins.2020 May; 12(5):328.

93. Dardiotis E, Sokratous M, Tsouris Z, Siokas V, Mentis AF, Aloizou AM, Michalopoulou A, Bogdanos DP, Xiromerisiou G, Deretzi G, Kountouras J. Association between Helicobacter pylori infection and GuillainBarré Syndrome: A meta-analysis. European Journal of Clinical Investigation. 2020 May; 50(5):e13218.

94. Deng $Q$, Wang $C$, Yu K, Wang Y, Yang Q, Zhang J, Xu X. Streptococcus bovis Contributes to the Development of Colorectal Cancer via Recruiting CD11b+ TLR-4+ Cells. Medical Science Monitor: International Medical Journal of Experimental and Clinical Research. 2020; 26:e921886-1.

95. Da Silva CC, Monteil MA, Davis EM.Overweight and obesity in children are associated with an abundance of Firmicutes and reduction of Bifidobacterium in their gastrointestinal microbiota. Childhood Obesity. 2020 Apr 1; 16(3):204-10.

96. Guo $P$, Tian $Z$, Kong $X$, Yang $L$, Shan $X$, Dong $B$, Ding $X$, Jing $X$, Jiang $C$, Jiang $N$, and $Y u$ Y. FadA promotes DNA damage and progression of Fusobacterium nucleatum -induced colorectal cancer through up-regulation of chk2.Journal of Experimental \& Clinical Cancer Research. 2020 Dec; 39(1):1-3.

97. Kazemian N, Mahmoudi M, Halperin F, Wu JC, Pakpour S. Gut microbiota and cardiovascular disease: opportunities and challenges. Microbiome.2020 Dec; 8(1):1-7. 